\title{
ILCEA
}

Revue de l'Institut des langues et cultures

d'Europe, Amérique, Afrique, Asie et Australie

$16 \mid 2012$

La culture progressiste à l'époque de la guerre froide

\section{À propos de la culture progressiste durant la guerre froide}

\section{Barbara Junge et Winfried Junge}

Traducteur : François Genton

\section{OpenEdition}

\section{Journals}

Édition électronique

URL : http://journals.openedition.org/ilcea/1248

DOI : $10.4000 /$ ilcea. 1248

ISSN : 2101-0609

Éditeur

UGA Éditions/Université Grenoble Alpes

Édition imprimée

ISBN : 978-2-84310-232-5

ISSN : $1639-6073$

\section{Référence électronique}

Barbara Junge et Winfried Junge, «À propos de la culture progressiste durant la guerre froide », ILCEA

[En ligne], 16 | 2012, mis en ligne le 04 juillet 2012, consulté le 22 mars 2021. URL : http://

journals.openedition.org/ilcea/1248; DOI : https://doi.org/10.4000/ilcea.1248

Ce document a été généré automatiquement le 22 mars 2021.

(c) ILCEA 


\title{
À propos de la culture progressiste durant la guerre froide
}

\author{
Barbara Junge et Winfried Junge \\ Traduction : François Genton
}

1 Culture progressiste, cela a toujours voulu dire culture qui ne contribue pas à la conservation de l'existant, le confirme et le célébre et qui est donc conservatrice, mais culture qui vise le changement. En des termes plus simples : politiquement elle est plutôt de gauche que de droite.

2 Lorsque l'Allemagne perdit la seconde guerre mondiale qu'elle avait commencée et que les puissances victorieuses la divisèrent, à l'Est se présenta la possibilité de suivre l'exemple de l'URSS et de construire une Allemagne qui ne serait plus l'ancienne. L'État bourgeois antifasciste deviendrait ensuite socialiste, puis communiste, ce qui signifiait: une société sans classes dans laquelle chacun vivrait non selon ses performances, mais selon ses besoins.

Le chemin passait par la socialisation des moyens de production. Le peuple deviendrait leur propriétaire, le pouvoir serait aux mains des travailleurs et des paysans, représentés par le Parti socialiste unifié d'Allemagne.

4 Ce but n'aurait pu être atteint par des élections libres. Les Allemands n'avaient pas la culture, la conscience, l'orientation politique nécessaires. Et la société allemande ne réunissait pas non plus les conditions s'y prêtant.

5 Le communisme, sous la forme du bolchevisme (ce qui ne signifiait rien d'autre que la domination de la majorité), passait il y a peu encore pour un spectre effrayant. Et Staline l'avait perverti en stalinisme.

6 Pour imposer le passage d'une société bourgeoise à une société socialiste, Marx avait estimé que la «dictature du prolétariat " était nécessaire. Mais sous la tutelle de l'Union soviétique, cette dictature pouvait recourir à des méthodes staliniennes.

7 Ainsi, dès le début, était marquée d'un vice de fabrication la tentative de transformer en pratique sociale l'idéal du socialisme, de faire de l'utopie "socialisme" un socialisme scientifique. Resta la dictature, la voie du socialisme démocratique ne fut pas 
trouvée. Le concept de démocratie socialiste ne resta qu'un autre mot pour désigner ce type de dictature.

8 Il s'agissait de rééduquer toute une population, plus précisément le citoyen de la zone d'occupation soviétique, plus tard RDA. Une rééducation qui n'eut lieu que partiellement à l'Ouest et qui n'y fut jamais un programme de société global.

Les médias aussi devaient servir cette cause. Aussi les actualités cinématographiques de la semaine et le film documentaire. Il n'y avait pas encore de télévision. Lénine déjà avait considéré le cinéma comme l'art le plus important de tous. Pour les raisons qui viennent d'être dites.

En RDA on comprenait le progrés comme ce qui est conforme et utile au développement socialiste.

11 L'art et le journalisme avaient à propager un exemple positif, leur fonction (apologétique) devait confirmer : nommer les acquis, les célébrer, encourager à juger révolus les aspects négatifs. Aider à la construction d'un nouvel ordre social, dépasser à jamais le capitalisme, la guerre, la dictature fasciste. Passer de la «dictature du prolétariat » à une véritable démocratie. Aider à imposer le pouvoir du peuple.

Réaliser un projet marxiste et scientifique : c'était une tâche que les communistes qui avaient survécu à la guerre hitlérienne n'étaient pas les seuls à vouloir accomplir dans l'enthousiasme. Nous autres, les jeunes, aussi. Après un siècle de capitalisme et deux guerres mondiales, construire une autre, meilleure Allemagne, ne pas répéter les fautes du passé.

13 En instaurant un ordre nouveau - une société sans classe, créer des hommes nouveaux. Et l'inverse aussi. Au lieu de s'entrebattre, se fixer un grand but libérateur et philanthropique : «Du moi vers le nous. »

14 La liberté en tant que vie sans misère, sans guerre, sans oppression, avec manque de perspectives. Croire, au sens de : promettre d'y travailler. Une grande idée.

15 La fonction critique de l'art et des médias devait se soumettre à cet objectif. Elle visait surtout la victoire sur le passé. Elle était moins bienvenue en tant qu'annonciatrice du futur, car critiquer le futur qui naissait, cela signifiait donner au passé une chance qu'on ne voulait pas lui donner.

16 La critique était donc vue d'un œil critique, suspecte. En termes simples, on disait : la critique, d'accord, mais pas pour elle-même.

17 La critique ne devait pas servir l'« ennemi de classe ». Et celui-ci, on l'entendait dans la même langue, à travers les médias occidentaux qui étaient présents sur tout le territoire de la RDA. Et lui, il ne voyait que les aspects négatifs, les échecs, les erreurs, les fautes, tout ce qu'on ne s'avouait pas. Ainsi, la RDA préférait exclure de la discussion publique ce qui n'allait pas, réaction interprétée comme une marque de faiblesse et un aveu d'échec - et comme la preuve de l'« absence de liberté » : une position sans issue.

18 Certes, on appelait de ses vœux une " critique utile ", mais à quelles conditions pouvaiton l'appeler « utile »?

19 Karl Gass, l'homme qui eut l'idée de la chronique des Enfants de Golzow, dit plus tard: "Je n'étais pas hostile envers la RDA, mais critique."

20 Gass a toujours eu des difficultés pour s'y faire comprendre. La suspicion crut avec les années pendant lesquelles la RDA, calfeutrée derrière le Mur, stagnait dans un monde qui connaissait un développement dynamique. 
21 La critique n'était pas à proprement parler un mot interdit, mais il valait mieux dire que l'on reconnaissait l'existence de contradictions dont on discutait. Ces contradictions, en tant que moteur du développement socialiste, n'étaient pas des contradictions "en soi ", encore moins des contradictions insurmontables. $\mathrm{Ne}$ s'occuper que d'elles, c'était créer un trouble superflu. Ainsi, une œuvre d'art pouvaitelle seulement se permettre de troubler si, par ailleurs, elle confirmait les aspects positifs du réel. Ce qui était bien, c'est qu'elle fît apparaître au moins une relation dialectique.

Découvrir, grâce à l'art, des contradictions, que le pouvoir politique n'avait pas encore permis de discuter, parce qu'elle n'avait pas de réponse à leur apporter, était risqué et difficile. L'art ne pouvait poser que les questions auxquelles lui-même pouvait répondre. Il s'agissait de l'orientation politique dans la direction donnée d'avance, voire de conseils pour la vie et restait dans les limites fixées d'en haut pour la discussion.

En voici une illustration: lorsque, pour des raisons de politique étrangère, on jugea inopportun que la RDA continue à fournir de l'uranium permettant la production de bombes atomiques soviétiques, on retira le film de Konrad Wolf Sonnensucher (Ceux qui cherchent le soleil, 1958, sur les mines d'uranium et les contacts entre travailleurs allemands et soviétiques dans les monts Métallifères de Saxe). Un classique de la DEFA dont l'interdiction fut suivie en 1965, pour d'autres raisons, par celle de la moitié de la production annuelle: le malaise face à la situation en RDA avait fait naître une « Nouvelle Vague » critique.

24 Certes, les arts ne doivent pas se voir comme la servante ou le valet de la politique officielle, comme on disait en haut lieu, ils devaient définir leur propre objet. Mais on ne les appréciait vraiment que s'ils se conduisaient en serviteurs de la cause.

Dans cette optique on ne faisait aucune différence entre l'art et le journalisme. Ce dernier devait être encore plus frontalement le porte-parole de la politique, ce qui signifiait : « Tout voir d'un point de vue socialiste. »

Ce dernier cessait d'être une notion bien définie ou un lieu sûr dès que la politique, pour des raisons de stratégie ou, plus simplement, d'opportunité, s'écartait de la voie habituelle. Alors, les artistes qui avaient jusque-là fait preuve d'une foi socialiste à toute épreuve, camarades méritants du Parti, s'exposaient à la critique, parce qu'ils refusaient un certain changement de cap, ou ne le comprenaient pas... ou n'en étaient pas même informés. Ainsi le Parti se privait-il parfois de ses alliés les plus connus, de l'écrivain Stefan Heym, du savant Robert Havemann, de l'auteur-compositeur Wolf Biermann. Certains quittaient la RDA, d'autres se retiraient ou étaient condamnés au silence, on leur interdisait d'exercer leur métier, on allait même jusqu'à les priver de leur citoyenneté. De combien d'hommes indispensables à une discussion des problèmes et des changements à apporter le Parti s'est privé !

Si un artiste connu était membre du Parti, il avait des privilèges, mais restait en premier lieu un camarade soumis à la discipline du Parti. Les missions et les sanctions $\mathrm{du}$ Parti visaient à discipliner. Le principe du "centralisme démocratique ", de « la fidélité à la ligne ", comme on le jugeait soi-même nécessaire, était l'expression de l'absence d'un processus décisionnaire allant de la base vers le sommet. Une telle perversion de la « démocratie socialiste » favorisait une passivité opportuniste. 
28 La RDA n'était pas un État à parti unique, mais la fusion des partis communiste et social-démocrate avait abouti à un parti dominant, le Parti socialiste unifié. À l'origine, l'idée était juste de fonder un " Parti de la classe ouvrière ", après les expériences de la République de Weimar et la confrontation des deux partis ouvriers qui avait permis, à leur corps défendant, l'avènement d'Hitler. Mais cela se passa à l'époque stalinienne et créa les conditions d'une «dictature progressiste». Au début de la guerre froide cela semblait la seule possibilité d'opposer la RDA en tant qu'Allemagne "alternative » à la renaissance d'une Allemagne bourgeoise et capitaliste.

$\mathrm{Au}$ départ, la RFA ne se contenta pas seulement de ne pas reconnaitre la RDA, elle la combattit aussi avec rage. L'exemple de cette alternative ne devait pas susciter de vocation. Et la doctrine Hallstein menaçait de rupture des relations diplomatiques avec la RFA tout État qui reconnaîtrait la RDA. Ce boycottage politique contribua à freiner le développement économique d'une RDA qui était une partie de l'Allemagne plus pauvre, moins industrialisée et, en plus, accablée par les réparations prélevées par les Soviétiques. Le dirigisme de l'économie planifiée se révéla en outre inférieur à une économie de marché qui se développait vite, après l'impulsion donnée par le Plan Marshall. L'État le plus faible des deux fut contraint à la défensive et perdit définitivement toute attractivité quand il commença à se barricader derrière le Mur. L'espoir de construire derrière ce Mur une nouvelle société et un nouvel ordre économique se révéla illusoire. La RDA n'avait plus seulement l'ennemi de classe comme adversaire, mais ses propres citoyens, qui se sentaient enfermés et n'avaient plus de motivation réelle pour donner le meilleur d'eux-mêmes pour ce «socialisme réel ».

Malheureusement le Parti n'a pas trouvé le moyen de regagner les citoyens par la confiance et une réelle participation aux décisions. La « sagesse collective » du Parti, à laquelle tout un chacun devait se soumettre était un slogan qui remplaçait des structures démocratiques et pluralistes. L'indispensable discussion à l'intérieur du Parti aurait été la première condition d'une telle orientation.

31 Le Parti socialiste unifié de RDA n'a pas suivi la voie empruntée par le Parti communiste de l'URSS sous Gorbatchev, parce qu'elle voyait se profiler dans la Perestroika et la Glasnost le début de la fin. La suite lui donna raison. L'Union soviétique finit par disparaître à cause de la Perestroika, la RDA parce qu'elle avait rejeté cette dernière. Elle n'aurait pu se maintenir que sous la forme qu'elle avait prise. Et si ce maintien n'avait pas entraîné une révolte des citoyens, l'effondrement économique aurait de toute façon entrâné sa disparition dans un avenir prévisible.

Mais revenons à la notion de "progressiste » du point de vue de la culture. S'il était progressiste de servir fidèlement la RDA ou de s'en réclamer, en écartant tous les doutes, il était immanquablement réactionnaire de la mettre en cause comme dictature ou du moins de la réformer et de mettre ainsi son existence en péril.

Aujourd'hui la notion de progrès a connu une transformation radicale. Celui qui a servi la RDA est un réactionnaire, si on se place d'un point de vue historique ou plutôt anhistorique. Les progressistes, c'étaient ceux qui s'opposèrent, qui ne la jugèrent digne d'être maintenue que si on la réformait et s'engagèrent dans ce sens.

La majorité des citoyens n'a pas rendu justice à ces progressistes-là. Des millions ont porté le « socialisme réel », même s'il n'était pas idéal, et souhaitaient qu'il se réforme 
sur cette base. Par « réel» ils entendaient un socialisme qui d'un côté était « quand même possible ", mais de l'autre " pas encore existant ».

Bertolt Brecht, qui fit le choix de vivre et de travailler en RDA, inscrivit ces paroles dans le cahier des charges des gouvernants qui emploient sans réfléchir le mot de progrès :

Le Progrès, ce n'est pas avoir des idées progressistes, mais progresser soi-même.

Le Progrès, c'est ce qui permet de progresser ou y contraint.

Je m'en tiens à cette définition et y recourrai volontiers à l'avenir.

37 Ce dont il faudrait discuter, c'est de la manière dont les documentaires de RDA ont traité cette problématique et reflété (on non) leur époque avec réalisme.

\section{AUTEURS}

BARBARA JUNGE

Cinéaste

WINFRIED JUNGE

Cinéaste 